\title{
MANAJEMEN SEKOLAH HIJAU BERWAWASAN LINGKUNGAN
}

\author{
V. Santi Paramita \\ santi.pramit@gmail.com \\ Dian Indiyati \\ dianinds@yahoo.com \\ P.Y.M. Wibowo Ndaruhadi \\ wibonda@yahoo.co.id \\ Amir Nuyman \\ nuyman72@gmail.com
}

\section{UNIVERSITAS JENDERAL ACHMAD YANI}

\begin{abstract}
ABSTRAK
Kegiatan pengabdian pada masyarakat ini bertujuan menerapkan manajemen sekolah hijau berwawasan lingkungan (eco green school management) melalui penanaman jiwa dan semangat cinta lingkungan serta mengubah perilaku warga sekolah." Kegiatan dilaksanakan melalui beberapa sup program, yaitu: 1) Program peninjauan dan penerapan kurikulum 2) Program penghijauan sekolah, 3) Program pembuatan alat peraga produksi kompos sederhana, 4) Program sosialisasi teknik pengolahan sampah organik menjadi kompos, 5) Program sosialisasi pembuatan sarana tanam vertikultur dan hidroponik, 6) Program sosialisasi pembuatan lubang biopori dan 7) Program edukasi kepada masyarakat tentang teknik tanam vertikultur dan hidroponik. Program dilaksanakan dengan melibatkan peran aktif guru dan siswa, diantaranya melalui penerapan kurikulum berwawasan lingkungan dalam seluruh mata pelajaran secara terintegrasi; sosialisasi program dalam beberapa media; praktik menanam, merawat, dan memanen hasil tanam; pembiasaan membuang dan memilah sampah serta workshop tenik tanam hidroponik, vertical garden dan proses pembuatan kompos sederhana. Secara keseluruhan program dapat terlaksana dengan baik, Namun keberhasilan pelaksanaan program sangat ditentukan oleh kreatifitas guru dan peran aktif siswa dalam pelaksanaan program-program cinta lingkungan. Pengawasan dan pengendalian kegiatan harus berprinsip pada konsistensi dan kedisiplinan dalam menjamin keberlangsungan dan keberhasilan program. Pada akhirnya, evaluasi perlu dilakukan secara berkala, agar dapat merancang program yang menarik pada periode berikutnya.
\end{abstract}

Kata Kunci: Manajemen sekolah hijau, Wawasan lingkungan. 


\section{PENDAHULUAN}

Pada hakikatnya, kurang optimalnya kesadaran untuk mencintai lingkungan bukan hanya masalah yang dihadapi pihak sekolah dengan segenap warga di dalamnya. Hal ini merupakan masalah utama yang dihadapi masyarakat Indonesia pada umumnya. Oleh karena itu, gerakan cinta lingkungan perlu digalakkan bagi seluruh masyarakat. Gerakan cinta lingkungan ini pada gilirannya mampu mencegah berbagai bencana yang disebabkan karena kondisi lingkungan yang buruk, seperti masalah banjir, longsor, kesulitan air bersih, serta polusi udara, air dan tanah yang berpotensi mengurangi kualitas kesehatan masyarakat

Gerakan cinta lingkungan ini akan efektif bila dimulai dari lingkungan sekolah, karena siswa biasanya patuh pada peraturan dan perintah/anjuran gurunya. Sejak dini, siswa sekolah ditanamkan jiwa dan semangat cinta lingkungan yang diterapkan melalui kegiatan belajar di kelas dan diimplementasikan langsung di lingkungan sekolah dan rumah dalam kehidupan sehari-hari. Penanaman jiwa dan semangat cinta lingkungan sejak dini diharapkan mampu membentuk karakter dan perilaku cinta lingkungan yang kuat. Pada tahap berikutnya, siswa yang telah memiliki jiwa serta semangat cinta lingkungan diharapkan mampu menjadi agen perubahan di lingkungan rumah dan sekitarnya. Vaske dan Kobrin (2001), Rosenberg, (2008), Bajd dan Lescanec (2011). Obyek kegiatan pengabdian pada masyarakat ini adalah 4 (empat) sekolah swasta pada jenjang yang berbeda, yaituTK Santa Theresia, SD Santa Maria, SD Santo Yusup dan SMP Santo Mikael yang berada di bawah naungan Yayasan Santo Dominikus.

Keempat sekolah $r$ tersebut
ditetapkan sebagai mitra program
pengabdian pada masyarakat karena tata
kelola sekolah berwawasan lingkungan
tertuang dalam program kerjanya.
Kawasan sekolah yang luas dengan
fasilitas yang baik dengan sumber daya

guru dan siswa yang memprioritaskan komitmen dan disiplin tinggi merupakan keunggulan mitra. Di samping itu, lokasi sekolah hanya berjarak sekitar 2 (dua) $\mathrm{km}$ dari lokasi Universitas Jenderal Achmad Yani selaku pelaksana program pengabdian pada masyarakat. Pemilihan subyek penelitian, yaitu siswa TK, SD dan SMP mengacu pada hasil penelitian Yilmaz et.al, (2004) serta Ozsoy et.al (2012) yang membuktikan bahwa penanaman sikap dan perilaku cinta lingkungan akan efektif jika ditanamkan sejak dini, sejak anak duduk di TK, SD dan SMP. Pada saat ini, jumlah seluruh siswa pada ke empat sekolah tersebut sebanyak 1293 orang dengan komposisi sebagai berikut: TK Santa Theresia 123 orang, SD Santa Maria 455 orang, SD Santo Yusup 371orang dan SMP Michael 344 orang. Sedangkan seluruh guru tetap berjumlah 69 orang yang tersebar pada TK Santa Theresia 12 orang, SD Santa Maria 19 orang, SD Santo Yusup 20 orang dan SMP Michael 18 orang. Jumlah seluruh staf administrasi 4 orang dan tenaga kebersihan 9 orang.

Luas lahan kawasan sekolah ini sekitar $21.350 \mathrm{~m}^{2}$, dengan berbagai fasilitas sebagai berikut:

a. Gedung sekolah 3 (tiga) lantai dengan konsep gedung hemat energi yang memiliki ruang dengan akses sinar matahari yang optimal serta didukung sirkulasi udara yang baik. Desain gedung sekolah ini berdampak penggunaan energi listrik yang minimal dengan ruangan tanpa AC yang mencerminkan desain gedung ramah lingkungan. Gedung terdiri dari 30 ruang kelas dan dilengkapi dengan ruang guru, ruang rapat, ruang guru piket, kantor kepala sekolah, dan kantor Yayasan.

b. Terdapat pula ruang perpustakaan, laboratorium komputer, laboratorium bahasa, UKS, kamar mandi dan aula.

c. Sekolah juga memiliki lapangan upacara / tempat bermain 
d. Tersedia pula lahan olah raga, toko, kantin, koperasi, poliklinik umum dan lahan parkir bersama.

Pada pagi hari, kawasan di depan sekolah dipergunakan oleh masyarakat sekitar sebagai pasar tumpah yang menjual beragam sayur-mayur, buah-buahan serta daging dan ikan. Seakan melengkapi keberadaan pasar tumpah tersebut, pada sisi luar halaman sekolah sebelah kanan, terdapat tempat pembuangan sampah sementara (TPS). Di samping itu, persis di sebelah kiri kawasan sekolah terdapat apartemen. Terdapat pula kawasan industri Leuwigajah-Cimahi yang terletak sekitar 3 $\mathrm{km}$ dari kawasan sekolah. Keberadaan pasar tumpah dan TPS serta kawasan industri tersebut menghadirkan berbagai persoalan, diantaranya:

a. Jalan menuju sekolah pada pagi hari menjadi sangat macet sehingga menimbulkan masalah polusi udara dan berpotensi menimbulkan masalah kesehatan akibat asap kendaraan bermotor

b. Sampah basah dari pasar serta sampah masyarakat yang dibuang ke TPS depan sekolah menimbulkan masalah polusi udara (bau yang menyengat, terutama pada saat musim hujan) dan polusi air tanah serta berpotensi menimbulkan masalah kesehatan bagi warga sekolah dan masyarakat sekitar

c. Kawasan industri yang terletak sekitar $3 \mathrm{~km}$ dari kawasan sekolah mengeluarkan asap pabrik yang menimbulkan masalah polusi udara

d. Apartemen yang terletak di sebelah kiri kawasan sekolah berpotensi menimbulkan masalah kesulitan air bersih.

Kepadatan penduduk sekitar, peningkatan pertumbuhan industri dan transportasi mengakibatkan pengeluaran emisi atau gas buang $\mathrm{CO}^{2}$ berbahaya yang mencapai $80 \%$ dari total gas emisi pembakaran. Hal ini merupakan faktor utama meningkatnya laju emisi gas rumah kaca ke atmosfer dan rusaknya fungsi hutan sebagai paru-paru dunia. Meningkatnya konsentrasi $\mathrm{CO}^{2}$ mengakibatkan penebalan lapisan atmosfer, sehingga panas matahari terperangkap dan mengganggu pelepasan panas bumi keluar atmosfer. Kondisi ini berakibat pada turunnya hujan asam yang membahayakan kelangsungan mahluk hidup. Dari semua kondisi tersebut, suhu permukaan bumi meningkat dan menimbulkan perubahan iklim yang drastis, hingga menyebabkan pemanasan global (global warming) (Pane dan Suryono, 2012).

Berdasarkan kondisi tersebut, maka pihak sekolah perlu mengelola kawasan internalnya menjadi kawasan yang bersih, teratur, dan sehat agar dapat meminimalisasi dampak polusi udara dan polusi air yang berpotensi mengganggu kesehatan. Dengan demikian, sekolah perlu berperan serta dalam kegiatan : 1) penghijauan kawasan; 2) pelestarian ketersediaan air bersih dan oksigen; 3) pengurangan/reduksi sampah; 4) pengolahan sampah menjadi produk yang bermanfaat; 5) pengantisipasian banjir; 6) pengurangan pemanasan global melalui penghematan penggunaan listrik, AC dan menghindari desain gedung kaca. Keseluruhan kegiatan penataan lingkungan ini perlu direncanakan, dilaksanakan serta dikendalikan secara terintegrasi melalui program manajemen sekolah hijau berwawasan lingkungan (Eco Green School Management).

Implementasi kegiatan ini dilaksanakan oleh seluruh warga sekolah dengan mempraktikkan langsung di lingkungan sekolah sesuai pendapat Palmberg dan Kuru (2000). Peran guru sangat sentral dalam memberikan wawasan, mengarahkan dan mencontohkan pelaksanaan program ini, sesuai pendapat Michael, et. al., (2007).

Beberapa permasalahan yang dihadapi mitra tersebut menginspirasi Tim Pengabdian Masyarakat UNJANI untuk bermitra dengan pihak Pimpinan sekolah untuk lebih berperan dalam meminimalisasi dampak lingkungan yang buruk bagi kesehatan warga sekolah dan masyarakat sekitarnya. Sekolah perlu 
mengelola kawasan internal sekolah agar menjadi kawasan yang bersih, teratur, dan sehat agar dapat meminimalisasi dampak polusi udara dan polusi air yang berpotensi mengganggu kesehatan.

Dengan demikian, penerapan program manajemen sekolah hijau berwawasan lingkungan berpotensi dapat diterapkan dengan baik secara berkelanjutan.

Pada sisi lain, keberhasilan penerapan gerakan cinta lingkungan perlu didukung dengan manajemen kegiatan yang terintegrasi dengan baik. Dengan demikian, perlu perencanaan (planning) yang menyeluruh dengan penetapan tujuan program yang jelas, pengorganisasian (organizing) melalui pembagian tugas dan wewenang yang jelas antara PT pengusul dengan mitranya, pelaksanaan (actuating) yang melibatkan seluruh warga sekolah serta pengendalian dan koordinasi (coordinating) antar seluruh pihak yang berkepentingan agar tujan program dapat tercapai, serta melakukan evaluasi pelaksanaan program (evaluating). Hasil penelitian Graaf (2006) serta Krnel dan Naglic (2009) menunjukkan bahwa siswa sekolah yang menerapkan eco-school memiliki sikap dan perilaku cinta lingkungan yang lebih baik dibandingkan siswa sekolah yang tidak menerapkannya.

Kegiatan ini perlu didukung pula dengan gaya kepemimpinan dari mitra, yaitu pihak sekolah, yang berkomitmen kuat dalam mewujudkan Program Manajeman Sekolah Hijau Berwawasan Lingkungan (Eco Green School Management) sehingga program dapat terus berjalan secara berkelanjutan (sustainable). Dengan demikian, manajemen sekolah hijau berwawasan lingkungan dapat dilaksanakan melalui 3 (tiga) aspek berikut ini :
a. Merencanakan
pengelolaan

kebersihan

, kesehatan, kehijauan, kenyamanan, keamanan dan ketertiban lingkungan sekolah. b. Mempersiapkan Sumber Daya Manusia sekolah dalam rangka membentuk perilaku sadar lingkungan pada setiap aktivitasnya.

c. Mengembangkan kurikulum dengan mengintegrasikan materi Pendidikan Lingkungan Hidup pada mata pelajaran yang relevan.

Sedangkan penilaian sekolah berwawasan lingkungan hidup akan bertumpu pada tiga aspek, yakni aspek manajemen, aspek kondisi fisik sekolah, dan aspek pemberdayaan warga sekolah.

Gerakan cinta lingkungan diawali dengan pencanangan kurikulum sekolah berbasis cinta lingkungan. Proses pembelajaran diwujudkan melalui kurikulum sekolah yang mengarah pada upaya pembentukan karakter dan perilaku guru dan siswa yang peduli lingkungan. Selain kegiatan pembelajaran di kelas, gerakan cinta lingkungan akan diimplementasikan secara nyata oleh para guru dan siswa di lingkungan sekolah dan lingkungan rumahnya. Kawasan lingkungan sekolah menjadi wahana utama tempat praktik penerapan perilaku cinta lingkungan. Hal ini sesuai dengan hasil penelitian Chapman dan Kamala (2001) serta Cincera dan Krajhanzl.(2013) yang telah mengimplementasikan gerakan cinta lingkngan bagi siswa SD dan SMP di India dan Filipina.

\section{METODE PELAKSANAAN}

Metode pelaksanaan Program Manajemen Sekolah Berwawasan Lingkungan (Eco Green School Management) akan diterapkan sesuai dengan sub-sub program sebagai berikut:

Tabel 2.1.

Metode Pelaksanaan Program Manajemen Sekolah Hijau Berwawasan Lingkungan (Eco Green School Management)

\begin{tabular}{|l|l|l|}
\hline NO & \multicolumn{1}{|c|}{ SUB PROGRAM } & \multicolumn{1}{c|}{ METODE } \\
\hline 1. & $\begin{array}{l}\text { Program peninjauan } \\
\text { kurikulum }\end{array}$ & $\boldsymbol{P} \begin{array}{l}\text { Focus Group } \\
\text { Discussion (FGD) }\end{array}$ \\
\hline
\end{tabular}




\begin{tabular}{|c|c|c|}
\hline & $\begin{array}{l}\text { berlandaskan semangat } \\
\text { cinta lingkungan }\end{array}$ & $>$ Workshop \\
\hline 2. & $\begin{array}{l}\text { Program penerapan } \\
\text { kurikulum } \\
\text { berlandaskan semangat } \\
\text { cinta lingkungan }\end{array}$ & $\begin{array}{l}\text { Ceramah } \\
\text { Penempelan } \\
\text { pengumuman/ } \\
\text { Spanduk/Poster } \\
>\text { Pelatihan } \\
>\text { Praktik dengan } \\
\text { pendampingan } \\
\text { Lomba/kompetisi }\end{array}$ \\
\hline 3. & $\begin{array}{l}\text { Program sekolah hijau } \\
\text { berwawasan } \\
\text { lingkungan (eco green } \\
\text { school) }\end{array}$ & $\begin{array}{l}\text { Pelatihan } \\
\text { Ceramah } \\
\text { Praktik dengan } \\
\text { pendampingan }\end{array}$ \\
\hline 4. & $\begin{array}{l}\text { Program pembuatan } \\
\text { alat peraga produksi } \\
\text { kompos sederhana }\end{array}$ & $\begin{array}{l}>\text { Workshop } \\
>\text { Ceramah } \\
>\text { Simulasi, praktik, }\end{array}$ \\
\hline 5. & $\begin{array}{l}\text { Program sosialisasi } \\
\text { teknik pengolahan } \\
\text { sampah organik } \\
\text { menjadi kompos }\end{array}$ & $\begin{array}{l}\text { Pelatihan } \\
\text { Ceramah } \\
\text { Simulasi, praktik, } \\
\text { pendampingan }\end{array}$ \\
\hline 6. & $\begin{array}{l}\text { Program sosialisasi } \\
\text { pembuatan sarana } \\
\text { tanam vertikultur dan } \\
\text { hidroponik }\end{array}$ & $\begin{array}{l}\text { Workshop } \\
>\text { Ceramah } \\
\text { Simulasi, praktik }\end{array}$ \\
\hline 7. & $\begin{array}{l}\text { Program sosialisasi } \\
\text { pembuatan lubang } \\
\text { biopori }\end{array}$ & $\begin{array}{l}>\text { Workshop } \\
>\text { Ceramah } \\
>\text { Simulasi, praktik, }\end{array}$ \\
\hline 8. & $\begin{array}{l}\text { Mengedukasi } \\
\text { masyarakat sekitar } \\
\text { tentang :pembuatan } \\
\text { kompos,teknik tanam } \\
\text { vertikultur dan } \\
\text { hidroponik }\end{array}$ & $\begin{array}{l}\text { Workshop } \\
\text { Ceramah } \\
\text { Simulasi, praktik, } \\
\text { pendampingan }\end{array}$ \\
\hline
\end{tabular}

Setiap sub program akan dilaksanakan dengan melibatkan peran aktif mitra dengan sasaran pencapaian indikator tiap sub program sehingga menjamin keberlanjutan program.

\section{HASIL DAN LUARAN}

Kegiatan manajemen sekolah hijau berwawasan lingkungan ini dilaksanakan berdasarkan 8 (delapan) sub program, yaitu:

1. Program peninjauan dan penerapan kurikulum berlandaskan semangat cinta lingkungan

Kegiatan dilakukan dengan mengintegrasikan materi lingkungan hidup dalam beberapa mata pelajaran secara terintegrasi. Pembentukan karakter dan perubahan perilaku siswa dilakukan dengan menekankan para siswa untuk selalu menerapkan kegiatan cinta lingkungan secara disiplin, konsisten dan berkelanjutan. Hal ini sesuai dengan hasil penelitian Graaf (2006), Krnel dan Naglic (2009), Boeve-de dan Van Petegem $(2011,2013)$ serta Murti (2013), yang menunjukkan bahwa siswa sekolah yang disiplin dan konsisten dalam menerapkan ecoschool akan memiliki sikap dan perilaku cinta lingkungan yang lebih baik. Tim penyusun dan penerapan kurikulum di TK Theresia, SD Santa Maria, SD Santo Yusup dan SMP Santo Mikael terdiri dari para guru dengan mengundang perwakilan orang tua siswa dan masyarakat sebagai narasumber.

2. Program sekolah hijau berwawasan lingkungan (eco green school)

Pelaksanaan program dilaksanakan melalui kegiatan penghijauan secara masal yang melibatkan seluruh siswa untuk menanam dalam pot (ada yang terbuat dari botol bekas), baik dengan teknik tanam konvensional dalam pot, teknik tanam vertikultur (Lukman, 2011) maupun teknik tanam hidroponik (Rakhman dkk, 2015; Roidah dan Syamsu, 2014). Jenis tanaman terdiri dari tanaman hias dan tanaman sayur. Setiap anak bertanggung jawab untuk menanam dan merawat tanaman secara teratur.

3. Program pembuatan alat peraga produksi kompos sederhana

Alat peraga produksi kompos sederhana berupa alat pencacah dan pengaduk sampah organik dengan system kayuh. Melalui alat ini, anak memahami bagaimana teknik pembuatan kompos sederhana dengan meminimalisasi kontak langsung dengan sampah organik.

4. Program sosialisasi teknik pengolahan sampah organik menjadi kompos

Kegiatan dilakukan melalui kegiatan workshop, dimana siswa dituntut berperan aktif dalam proses pemilahan 
sampah organik dan non organik, kemudian mengolah sampah organik dengan mencacahnya, memberikan larutan kimia, menimbun dan membalikkan sampah dengan mesin pengaduk sehingga menghasilkan kompos (Yuniwati dkk, 2012).

5. Program sosialisasi pembuatan sarana tanam vertikultur dan hidroponik

Program sosialisasi pembuatan sarana tanam vertikultur (Lukman, 2011) dan hidroponik (Rakhman dkk, 2015; Roidah dan Syamsu, 2014). dilakukan dengan cara memberikan pelatihan kepada para guru. Selanjutnya para guru yang akan menjelaskan teknik tanam vertikultur dan hidroponik kepada siswa didiknya.

6. Program sosialisasi pembuatan lubang biopori.

Program sosialisasi pembuatan lubang biopori dilakukan dengan cara memberikan pelatihan kepada para guru. Selanjutnya para guru yang akan menjelaskan teknik pembuatan lubang biopori kepada siswa didiknya.

7. Mengedukasi masyarakat sekitar tentang pembuatan kompos teknik tanam vertikultur dan hidroponik. Kegiatan ini merupakan kegiatan yang dirancang akan dilaksanakan sebagai tindak lanjut kegiatan yang telah dilaksanakan tahun ini. Tujuan dari kegiatan ini adalah turut menyadarkan orang tua siswa dan masyarakat tentang pentingnya menjaga dan melestarikan lingkungan. Peserta pelatihan juga diajarkan untuk memahami teknik tanam vertikultur dan hidroponik sehingga mampu mempraktikkan dalam lingkungan rumahnya dengan lahan yang terbatas.

Pelaksanaan kegiatan manajemen sekolah hijau berwawasan lingkungan ini menghasilkan model penerapan cinta lingkungan yang melaksanakan secara terintegasi kegiatan-kegiatan berikut:

1. Penerapan kurikulum berbasis cinta lingkungan melalui pengintegrasian wawasan lingkungan ke dalam seluruh mata pelajaran, kegiatan intra dan ekstra kurikuler serta pengelolaan kawasan sekolah yang berwawasan lingkungan.

2. Perubahan perilaku guru dan siswa dalam memahami dan menyikapi berbagai masalah lingkungan.

3. Perubahan kawasan sekolah menjadi lebih hijau, bersih, dan sehat.

4. Penguasaan guru dan siswa dalam teknik tanam vertikultur dan hidroponik pada program penghijauan di lahan yang terbatas.

5. Peningkatan kreativitas guru dan anak dalam pemanfaatan barang bekas yang berasal dari sampah non organik.

6. Pemahaman guru dan siswa tentang metode pengkomposan sederhana didukung dengan alat peraga mesin pencacah dan pengaduk kompos.

Sedangkan rencana target luaran yang akan dihasilkan dari Program Manajemen Sekolah Hijau Berwawasan Lingkungan (Eco Green School Management) ini adalah

1. Publikasi pada Jurnal Nasional dan Media Cetak/Online untuk menginformasikan kegiatan yang telah dilaksanakan kepada masyarakat pendidikan dan masyarakat umum.

2. Peningkatan kuantitas dan kualitas produk, dengan mengasilkan :

- 1 (satu) unit alat peraga pencacah dan pengaduk kompos dengan penggerak sistem kayuh.

- 2 (dua) unit sarana tanam hidroponik NFT system dengan @ 28 netpot, meliputi paralon, motor penggerak aliran air, rockwool, nutrisi tanaman, dan bibit sayuran.

- 3 (tiga) unit sarana tanam vertical garden untuk tanaman hias meliputi besi penyangga; media tanam beserta tanaman hias (@ ukuran 1,5 x 1,5) dengan 150 pot dari botol sprite bekas, lengkap dengan media tanam dan tanaman hias. 
- 8 (delapan) unit sarana tanam vertical garden untuk sayuran meliputi kerangka besi penyangga; lengkap dengan media tanam beserta 120 buah pot dan bibit sayuannya (ukuran $30 \mathrm{~cm}$ x $80 \mathrm{~cm}$ x $120 \mathrm{~cm}$ ).

- 120 (seratus dua puluh pot) lekap dengan tanaman hiasnya yang diletakkan di atas dinding pembatas kelas.

- 36 (tiga puluh enam) unit penyiram bunga.

- 48 (empat puluh delapan) poster dalam bingkai kayu untuk sosialisasi cinta lingkungan.

- 8 (dua) set tempat sampah organik dan non organik, masing-masing 2 (dua) set untuk setiap unit sekolah.

3. Peningkatan pemahaman dan keterampilan masyarakat, melalui:

- Workshop penanaman dan perawatan tanaman vertical garden.

- Workshop penanaman dan perawatan tanaman hidroponik.

- Workshop pembuatan kompos sederhana.

4. Peningkatan ketentraman/kesehatan masyarakat karena lingkungan sekolah semakin bersih dan sehat

\section{KESIMPULAN}

Manajemen sekolah hijau berbasis lingkungan (eco green school management) telah dilaksanakan oleh TK Theresia, SD Santa Maria, SD Santo Yusup dan SMP Santo Mikael yang seluruhnya di bawah naungan Yayasan Santo Dominikus. Perencanaan kegiatan diawali dengan penyusunan kurikulum berbasis lingkungan hidup yang diimplementasikan secara terintegasi pada seluruh mata pelajaran. Pengorganisasian kegiatan dipimpin oleh Kepala Sekolah sebagai penanggung jawab kegiatan dengan dukungan seluruh guru agar agar program dapat berjalan dengan baik dan berkesinambungan.

Keberhasilan pelaksanaan program sangat ditentukan oleh aktivitas kreatif guru dalam merancang program-program cinta lingkungan dan partisipatif aktif dari siswa. Pengawasan dan pengendalian kegiatan harus berprinsip pada konsistensi, kedisiplinan dalam menjamin keberhasilan dan keberlangsungan program. Pada akhirnya, evaluasi perlu dilakukan secara berkala setiap tahun agar dapat merancang program yang menarik pada tahun berikutnya.

Pada tahapan berikutnya, disarankan agar pelaksanaan kegiatan manajemen hijau berwawasan lingkungan dapat melibatkan peranaktif orang tua dan masyarakat di sekitar sekolah.

\section{REFERENSI}

Bajd, B. dan Leščanec, T. (2011). The Influence of The Eco-School And Healthy School Projects on Environmentally Responsible Behavior of Primary School Pupils. Education and Health Care, 21, pp.79-85.

Boeve-de Pauw, J. dan Van Petegem P.(2011). The Effect of Flemish Eco-Schools on Student Environmental Knowledge, Attitudes, and Affect. International Journal of Science Education. Vol. 33. No. 11, pp 1513-1538.

Boeve-de Pauw, J. Van Petegem, Peter. (2013). The Effect of Eco-Schools on Children's Environmental Values and Behaviour. Journal of Biological Education, Vol. 47, No. 2, pp 96-103

Chapman, D dan Sharma, K. (2001). Environmental Attitudes and Behavior of Primary and Secondary Students in Asian Cities: An Overview Strategy for Implementing an Eco-schools Programme. The Environmentalist. Volume 21, Issue 4,pp 265-272.

Cincera, J dan Krajhanzl, J. (2013). EcoSchools: What Factors Influence 
Pupils' Action Competence for ProEnvironmental Behaviour? Journal of Cleaner Production Vol 61, No. 25, pp 117-121.

Graaf, A. V. D. (2006). ECO-Schools: Trends and Divergences. A Comparative Study on ECO-School Development Processes in 13 Countries. Australian Journal of Environmental Education, Vol. 22, Issue 1, pp 123-125

Krnel, D. dan Naglic, S. (2009). Environmental Literacy Comparison Between Eco-Schools and Ordinary Schools in Slovenia. Science Education International, Vol. 20, No.1, pp 5-24.

Lukman, L.(2011). Teknologi Budidaya Tanaman Sayuran Secara Vertikultur Oleh Balai Penelitian Tanaman Sayuran

(www.litbang.pertanian.go.id)

Michail, S, Stamou, A.G. dan Stamou, G. P. (2007). Greek Primary School Teachers' Understanding of Current Environmental Issues: An Exploration of Their Environmental Knowledge and Images of Nature. Education, Vol. 91, No. 2, pp 244259.

Murti, R. A. (2013). Pembentukan Karakter Siswa Melalui Sekolah Berwawasan Lingkungan (Studi Deskriptif Di SMA Semen Gresik). Jurnal Kajian Moral dan Kewarganegaraan, No. 1 Vol. 2 Tahun 2013, hlm. 352-366

Ozsoy, S., Ertepinar, H., dan Saglam, N. (2012). Can Eco-Schools Improve Elementary School Students' Environmental Literacy Levels? Asia-Pacific Forum on Science Learning and Teaching, Vol. 13, Issue 2, Article 3.

Pane, K. A., dan Suryono. (2012).Kajian Prinsip 'Eco Friendly Architecture', Studi Kasus: Sidwell Friends Middle
School. Jurnal Arsitektur Daseng Unsrat Manado, Vol 1, No 1, pp 5229.

Palmberg, I. E. dan Kuru, J. (2000). Outdoor Activities As A Basis For Environmental Responsibility. The Journal of Environmental Education, Vol. 31, No. 44, pp 32-36.

Rakhman, A., Lanya, B., Rosadi, R.A. Bustomi, K., Zen, M. (2015). Pertumbuhan Tanaman Sawi Menggunakan Sistem Hidroponik Dan Akuaponik. Jurnal Teknik Pertanian Lampung, Vol.4, No. 4 : 245-254.

Roidah, I.S. (2014). Pemanfaatan Lahan Dengan Menggunakan Sistem Hidroponik. Jurnal Universitas Tulungagung Bonorowo, Vol. 1. No.2 : 43-49.

Rosenberg, E. (2008). Eco-Schools and the Quality of Education in South Africa: Realising the Potential. Southern African Journal of Environmental Education, Vol. 25 No. 1.

Vaske, J.J., dan Kobrin, K.C. (2001). Place Attachment And Environmentally Responsible Behavior. Journal of Environmental Education, Vol.32, No.4,pp 16-21.

Yılmaz, Ö., Boone, W.J., Andersen, H.O. (2004). Views of Elementary and Middle School Turkish Students Toward Environmental Issues. International Journal of Science Education, 27(12), pp. 1527-1546.

Yuniwati, M., Iskarima, F., dan Padulemba, A. (2012). Optimasi Kondisi Proses Pembuatan Kompos dari Sampah Oganik dengan Cara Fermentasi Menggunakan EM4. Jurnal Teknologi, Vol. 5 No. 2, hlm. 172-181. 